\title{
CLASSIFICATION OF RESTRAINTS IN THE OPTIMIZATION PROBLEM OF A COLD-FORMED PROFILE
}

\author{
Agnieszka Łukowicz', Elżbieta Urbańska-Galewska', \\ Patryk Deniziak', Małgorzata Gordziej-Zagórowska' ${ }^{1}$ \\ 1 Faculty of Civil and Environmental Engineering, Gdansk University of Technology, Narutowicza 11/12, 80-233 \\ Gdańsk, Poland, e-mail: agnlukow@pg.gda.pl, ugalew@pg.gda.pl, patdeniz@pg.gda.pl, malgor@pg.gda.pl
}

Received: 2015.10.06

Accepted: 2015.11.14

Published: 2015.12.04

\begin{abstract}
This work describes the restraints in the optimization problem. This is an important and complicated issue because it requires taking into account a vast range of information related to the design and production. In order to describe the relations of a specific optimization problem, it is essential to adopt appropriate criteria and to collect information on all kinds of restraints, i.e. boundary conditions. The following paper verifies the various restraints and defines three subsets: design assumptions, technological limitations and standard conditions. The provided classification was made with reference to the analysis of the construction applicability of the newly patented cold-formed profile.
\end{abstract}

Keywords: steel structures, thin-walled elements, cold-formed sections.

\section{INTRODUCTION}

Structural optimization is an important issue in the world of engineers for a long time. It is a complicated problem due to a huge database to be considered, related to design and erection of structures. The investing process involves a multitude of interconnected variables, acting on a final structure. A high number of variables makes it difficult to find a relevant optimization method. A universal one, covering all issues does not exist. It is possible to restrict a field - construction of a steel structures of a given kind (e.g. typical single-storey steel structures) and to focus on a dedicated solution.

System construction of steel structures made of cold-formed profiles is a rapidly developing branch of steel structural industry [1]. The number of manufactories to work with this branch is still increasing. The applied design variants are typified and indexed in catalogues. Both development of steel structural industry and a trend to minimize production costs lead to the conclusion, that typization of the structural variants taken alone is insufficient. Optimization field should be enhanced, to cover the problems of structural stability and resistance as well as fabrication technology. In order to formulate the optimization relationships the relevant criterion should be assumed and fulfilled.

Another key issue is collecting sufficient information on the limiting restraints - boundary conditions. The article verifies the limitations creating three subsets: design assumptions, technological limitations and standard conditions. This classification yields from the analysis of structural application of a newly patented coldformed profile.

\section{LIGHT GAUGE STEEL STRUCTURES MADE OF COLD-FORMED PROFILES}

The last two decades detect the advent of typical system structures in the field of steel construction. This kind of erection significantly improves the structural assembly, thus time and cost reduction. Simple variants of production and warehouse halls, in the form of light gauge steel 
structures made of thin-walled cold-formed profiles are most common in this branch.

These profiles exhibit numerous advantages: relatively low self-weight, it reflects in overall cost of the project [2]. It is also worth noting that the cold-formed profiles due to assumptions of their technology, take various cross-section shapes. This brings about broad perspectives of application of these profiles in various types of construction, improving the overall structural aesthetics.

Unfortunately, production of this kind of profiles may be complicated and expensive. In addition, thin-walled cold-formed members are sensitive to local transportation defects, thus higher attention and care are required during construction. The design process of these elements is complicated and time-consuming. Taking into account the abovementioned advantages of cold-formed profiles and the trend towards more developed constructions, it is a key question how to help designers in obtaining new, interesting and economic solutions. A possible solution of this problem is introducing a new, innovative profile on the building material market, to become a basic component of load-carrying structures, performed in a systematic manner. Keeping in mind the pros and cons of cold-formed thin-walled profiles and standard conditions of its production optimization of its geometric parameters should be done in the light of cost minimization of structures made of such profiles.

\section{OPTIMIZATION PROBLEM}

The optimization problem is a method to detect the best-fit solution, i.e. extreme of the optimization function (objective function) for a given problem, due to a given criterion, resulting in analysing its four components [3].

First of all, optimization criteria have to be determined, being a fulfilment measure of a given objective. In steel construction the major aim is structural cost minimization, linked with the reduction of mass (weight) of a structure. Key problems are the shortest time and the highest fabrication quality and versatility of a structure, making it possible to serve various purposes. In fact it is not possible to achieve extreme value of every objective function at once, compromises are unavoidable as optimization is a multi-criterion problem.
In the next step, optimization parameters are assumed, independent of a designer, resulting from technology aspects or standard documents. They are numerical values or functions defining any structure or system. The subsequent factor is the set of design variables, which are designerdependent, of a crucial structural role - a properly adjusted set of design variables acts strongly on the optimization result. Based on optimization parameters and design variables a broad set of the so-called restraints may be created, to match the features of a problem considered. Considering all the above mentioned components solution of an optimization problem may be defined as a proper selection of design variables leading to extreme values of given criteria, under specified restraints [3].

The optimization criteria, optimization parameters and design variables are easy to be precisely formulated by a designer dealing with optimization of a given problem. Attention should be paid to a set of restraints to be thoroughly analysed and grouped, due to its vast range, in order to achieve a goal. Structural design is the process of assuming cross-section of members to achieve minimum structural mass, simultaneously achieving resistance and stiffness criteria. Optimal structure may be designed given a vast catalogue of profiles. A novel profile in Figure 1 is intended for the load-carrying members of single storey buildings. Geometric optimization of such a profile is possible for the sake of its structural application. This procedure is presented in the paper for a novel cold-formed profile.

\section{CLASSIFICATION OF RESTRAINTS}

Analysis was made assuming a cold-formed profile patented two years ago (Fig. 1). The innovative cross-section of a trapezoidal layout detects a longitudinal assembly slot to be mounted a system joint to assemble structural elements. It is a novel design of a steel profile manufacture, planning to launch a new structural system based on these profiles.

The analyzed profile should be light, versatile in its applications, manufactured on stock, easy and economical in production. In order to face these requirements optimal geometric parameters should be stated. Geometric optimization is effective in the case of a detailed classification of all restraints [2], namely: 
a)

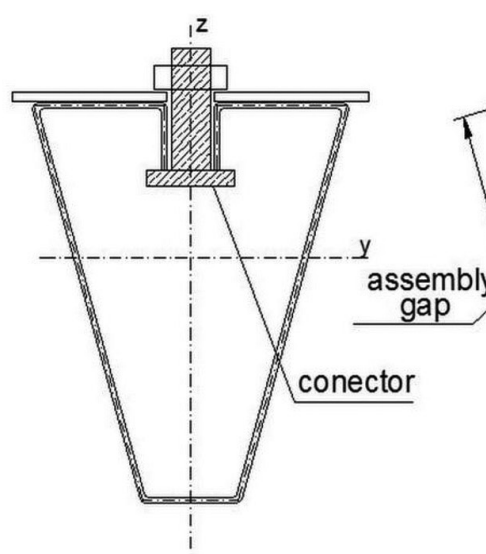

b)

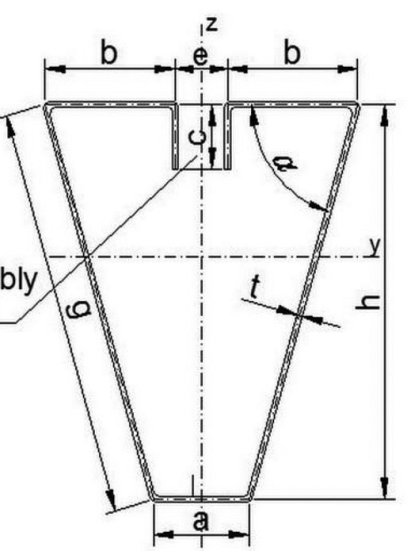

c)

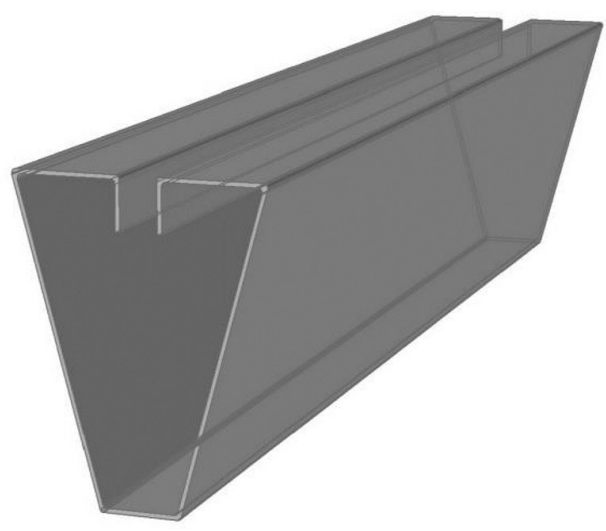

Fig. 1. A cross section with connector (a), geometric parameters of a cross section (b), axonometric view (c)

- restraints due to design assumptions,

- restraints due to standard documents,

- restraints due to the assumed manufacturing technology.

\section{RESTRAINTS DUE TO DESIGN ASSUMPTION}

The design assumptions are strictly linked with structure type and request for a given element type. Both are defined by investor, architect and limited by site conditions, location and destination of a designed structure. The presented description allows to apply the introduced profile as an element of a typical single-story steel structure, thus one of the design assumptions concerns the cross-sectional shape.

The element considered is a trapezoidal open thin-walled profile, every side is properly dimensioned. The ,a" side, a shorter base, is limited to an interval $60-110 \mathrm{~mm}$. It comes from cutting oval openings, to be later used in centering sheets on a bending press, in order to neglect the aligning operation with its cost. The openings make it possible to assemble a given structural type, whose magnitude acts on a minimum ,a” dimension equal to $60 \mathrm{~mm}$.

The next key parameter is a width of a mounting slot „e", determined by location of a system joint to assemble a structure and technology of profile bending. The value was assumed $60 \mathrm{~mm}$. The construction type to introduce an element was assumed a single-bay hall of a gabled roof of given dimensions (Fig. 2).

It was also assumed that structural location based on demand for buildings of that type is Northern Poland, thus 3rd snow load zone and 2nd wind load zone assumed. The maximum elevation of a structure on a Kashubian Lake District is Wieżyca, $300 \mathrm{~m}$ above sea level. Next, two static models were analyzed to define a given

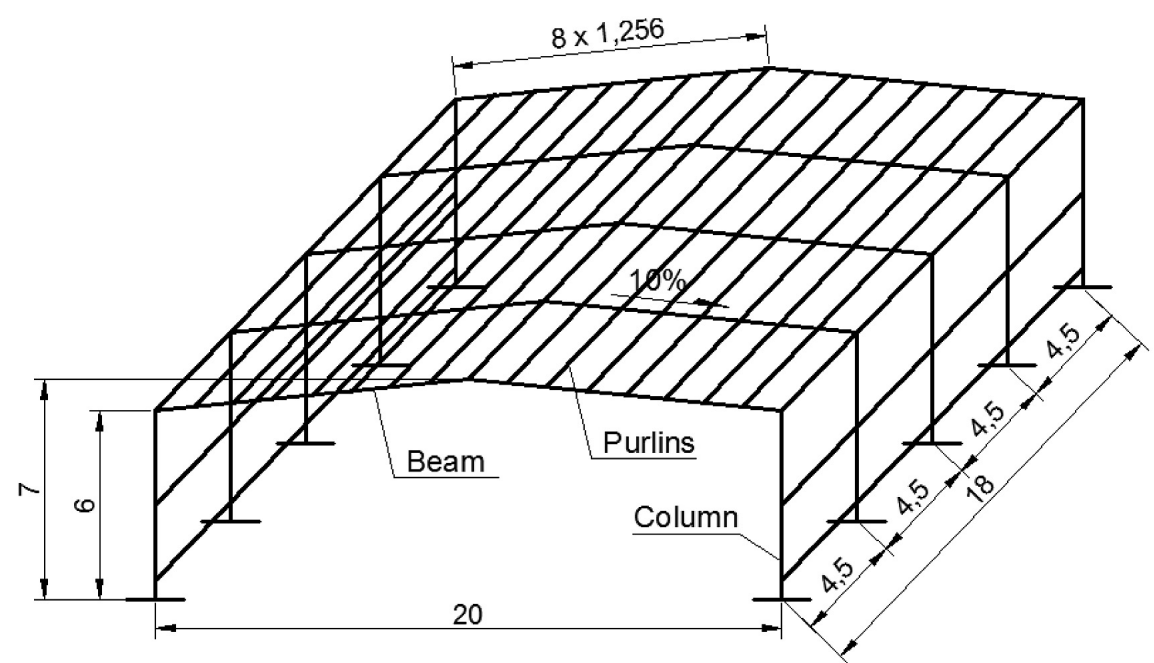

Fig. 2. Draft of a typical dimensioned structure 
a)

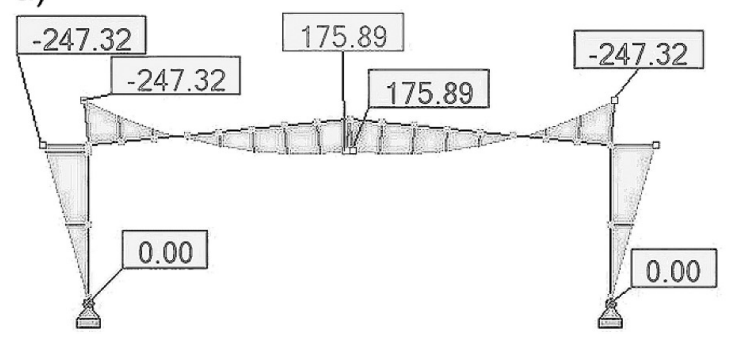

c)

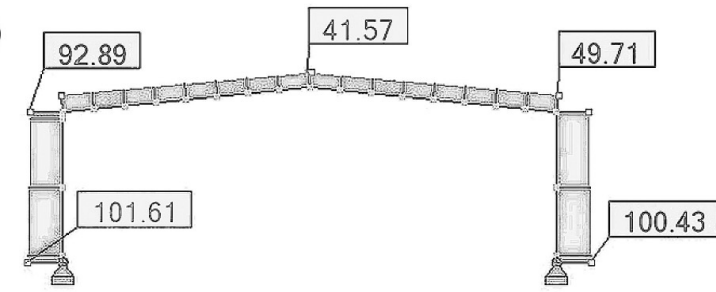

b)

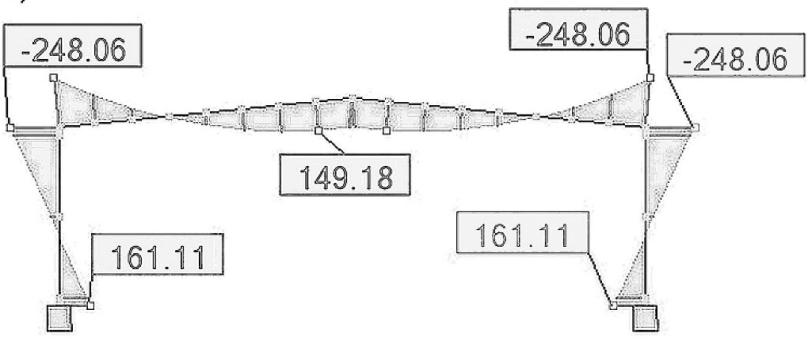

d)

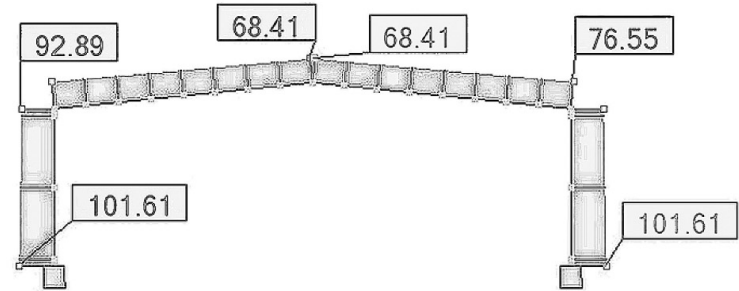

f)

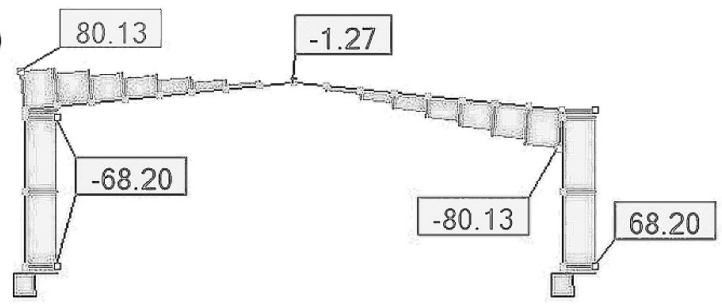

Fig. 3. Cross-sectional force diagrams: a, b) $\mathrm{M}[\mathrm{kNm}]$, c, d) $\mathrm{N}[\mathrm{kN}]$, e, f) $\mathrm{V}[\mathrm{kN}]$, structural models with a pin support (a, c, e) and a fixed support (b, d, f)

structure: a rigid joint frame (Fig. $3 \mathrm{~b}, \mathrm{~d}$ and $\mathrm{f}$ ) and a frame pin-supported on its footing (Fig. 3a, c and e).

The presented diagrams show that an optimal cross-sectional force diagram concerns the rigid joint frame. It results in beam midspan moments reduced by $15 \%$ acting on stability and a variety of structural layout. In addition, high cross-sectional forces at joints triggered an element of an appropriate stiffness, carrying stresses and joining elements at nodes: columns with foundations, columns with beams, beams in their span, beams at their midspan (Fig. 4a). It is a closed, welded cold-formed element - a muff (Fig. 4b).

\section{RESTRAINTS DUE TO STANDARD DOCUMENTS}

Assuming that a designed system includes class 4 cold-formed thin-walled elements, values of wall slenderness, radius of bending, flexibility of side bracing of open cross-sections. The feasibility analysis was based on [4, 5 and 6]. These references led to the third subset - restraints due to standard documents.

The computations were made of a rigid joint structural model, favorable due to bending moment distribution. The diagram for a beam and a column (Fig. 3b) made it necessary to determine a)

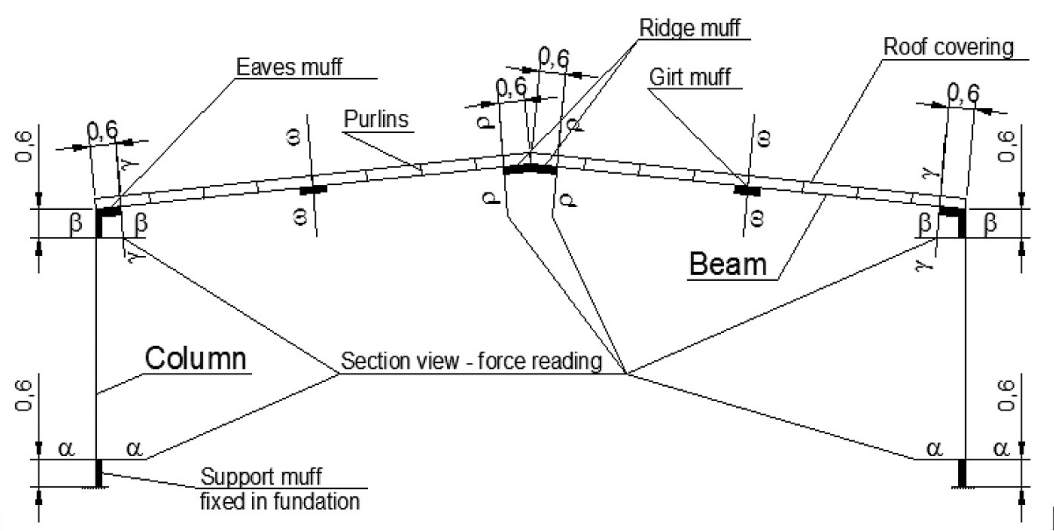

b)

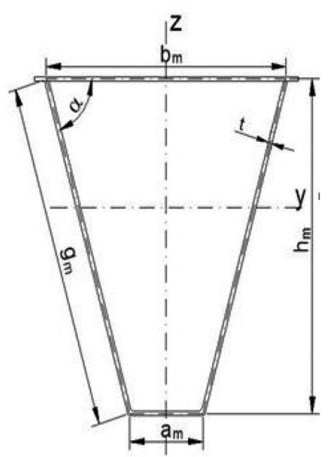

Fig. 4. The load-carrying frame model, layout of the muffs, b) cross-section of a muff 
geometric parameters and resistances for two locations of a cross-section on structural axes, illustrated in Figure 5.

Based on the abovementioned information resistance and stability of a cold-formed element were analyzed. These criteria require a huge computational expenditure, due to relations in $[4,5,6]$. First of all, the standard guidelines led to appropriate dimensional proportions in order to assure a relevant stiffness and to avoid an early instability of edge stiffeners, occurring in open crosssections. The bend radius was taken equal to wall thickness, to be simply neglected in calculations. The restraint set was complemented by the following relations between wall dimensions: $0,2<\mathrm{c} / \mathrm{b}<$ $0,6, \mathrm{~b} / \mathrm{t}<60, \mathrm{c} / \mathrm{t}<50, \mathrm{~h} / \mathrm{t}<\operatorname{sinf}, \mathrm{a} / \mathrm{t}<500$. Crosssectional characteristics require data on sensitivity of a side bracing (side $\mathrm{b}$ and $\mathrm{c}$ ) to distortional buckling, the other walls ( $g$ and $h$ ) to a local buckling. The computations were made for three load cases shown in Figures 5b, c and d, with appropriate effective cross-sectional areas (Fig. 6).

In the compression case the cross-sectional area is reduced, the middle part of sloped element is unloaded, upper and sloped boundary element become thinner - thickness reduction occurs due to distortional buckling.

a)

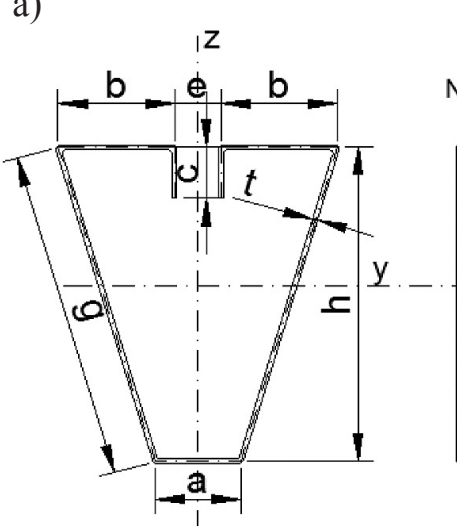

b)

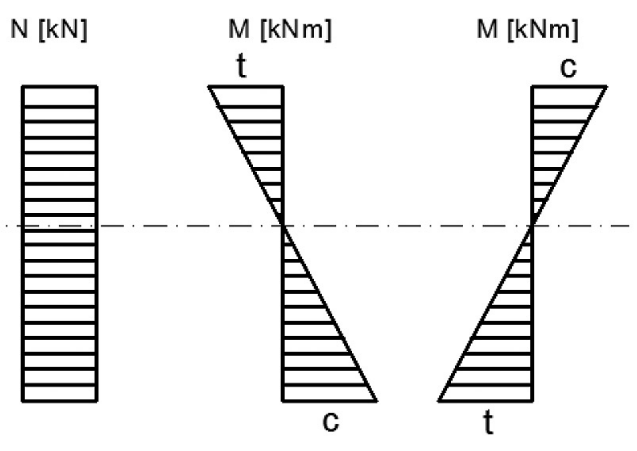

Fig. 5. a) Geometric parameters of the cross section, b) normal stresses diagram at axial compression, c) normal stresses diagram at bending - side „a” at compression, d) normal stresses diagram at bending - side „a” at tension

a)

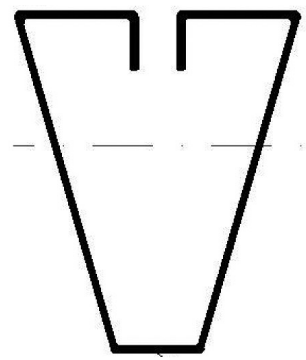

b)

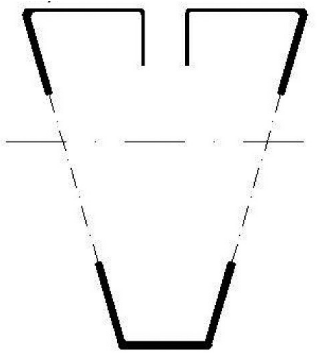

c)

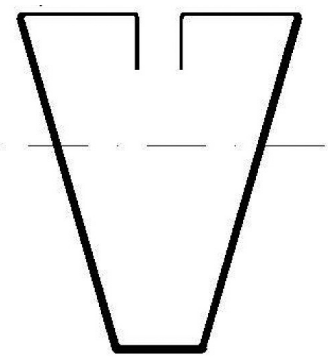

d)

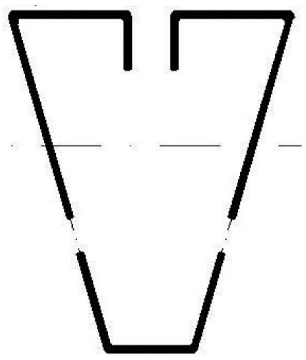

Fig. 6. a) Gross cross-section, b) cross-section at axial compression, c) cross-section at bending - side "a" at tension, d) cross-section at bending - side "a" at compression. 
matic type, bending presses, roll benders. Their technical parameters, like magnitude, efficiency, differ significantly. The highest efficiency corresponds to a roll bender, however, a developed and costly device, both in purchase and operation due to exchange of bending parts. A novel profile initials limited production. Thus, bending this profile makes it preferable a bending brake, less efficient than a roll bender but easier to exchange profiling bars, cheaper in purchase and service.

The bending press was assumed of maximum length $8 \mathrm{~m}$, assumed a shape, type and size of a bending razor. The following limitations come next: maximum profile depth $450 \mathrm{~mm}$, wall dimensions "b", "c" and "g" defining the profile perimeter length and dimensions of the metal sheets ordered. Additionally a bending device in a bending press detects a specified thrust, this type allows to bend the profiles of a thickness from 1 $\mathrm{mm}$ to $8 \mathrm{~mm}$.

One of the major innovative assumptions of a presented profile is its manufacturing involving corrosion protection - hot dip zinc coating. It was decided to apply a zinc coating bath $7 \mathrm{~m}$ long, thus a limitation on the element length comes consequently.

\section{RESTRAINTS SET}

There are links among all considered restraints, illustrated in Figure 7. The whole number of restraints mentioned here should be thor- oughly analyzed and considered, both in the new element creation and its optimization. In addition, as it may be seen on the graph, ultimate, serviceability and stability limit state criteria only, assuming a minimum mass objective, will not lead to a unique solution of a minimum cost problem. The sets of technological guidelines and design assumption, with their interaction may lead to an economically effective solution given a minimum mass assumption.

\section{CONCLUSIONS}

The calculations of the hall load-carrying members (columns and beams) are work- and time-consuming. The standard EN 1993-1-3 which is not widespread up till now requires a solid background on cold-formed thin-walled profiles. Thus it was concluded that an appropriate electronic algorithm to compute cross-sectional geometric parameters and to check resistance, stability and serviceability of thin-walled cold-formed elements will allow for an easier application of these profiles for a variety of structural types, not the systematic only. An optimization algorithm of a given profile, imposing all the restraints, especially due to technology, will lead to an easy and straightforward objective function of an optimization problem. This is a possible encouragement for the designers to propose these kinds of structures for various bids and to simplify real cost estimation of investments.

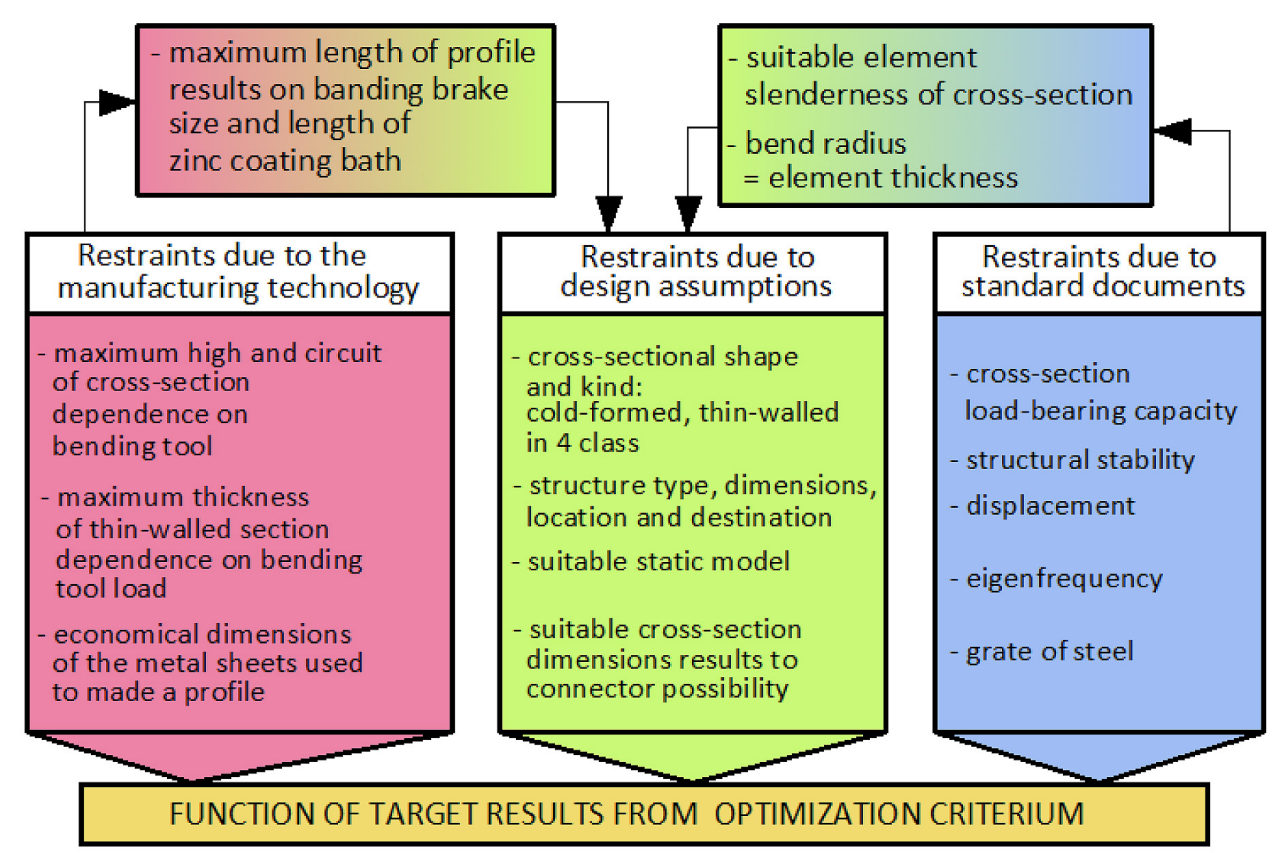

Fig. 7. A graph dividing the restraint set into three subsets 


\section{REFERENCES}

1. Urbańska-Galewska E., Łukowicz A.: O możliwościach optymalizacji konstrukcji stalowych. Nowoczesne Hale, 4, 2011, 26-30.

2. Łukowicz A., Urbańska-Galewska E.: Wpływ ograniczeń technologicznych na dobór parametrów przekroju kształtownika giętego. Zeszyty Naukowe Politechniki Rzeszowskiej: Budownictwo i Inżynieria Środowiska, z. 59, 3(II), 2012, 225-232.
3. Szymczak Cz.: Elementy teorii projektowania. PWN, Warszawa 1998.

4. EN-1993-1-1 Design of steel structures - General rules and rules for building.

5. EN-1993-1-3 Design of steel structures - General rules. Supplementary rules for cold-formed members and sheeting.

6. EN-1993-1-5 Design of steel structures - Plated structural elements. 